\title{
Safety and Driving Ability following Low-Dose Propofol Sedation
}

\author{
Akira Horiuchi $^{a}$ Yoshiko Nakayama ${ }^{b}$ Yoshihiko Katsuyama ${ }^{c}$ Shigeru Ohmoric \\ Yasuyuki Ichise $^{a}$ Naoki Tanaka ${ }^{a}$ \\ Departments of a Gastroenterology and ${ }^{b}$ Pediatrics, Showa Inan General Hospital, Komagane, and \\ 'Division of Pharmacy, Shinshu University Hospital, Matsumoto, Japan
}

\section{Key Words}

Propofol · Sedation · Esophagogastroduodenoscopy •

Driving ability $\cdot E G D$

\begin{abstract}
Background and Aim: Automobile driving is prohibited after midazolam sedation because of the slow recovery of psychomotor function. This study prospectively assessed the safety of low-dose propofol sedation (study 1) and compared driving ability following propofol and midazolam sedation (study 2). Methods: Study 1: We prospectively investigated bolus injection of a low-dose of propofol $(40-80 \mathrm{mg}$ for $<70$ years and $30 \mathrm{mg}$ for $\geq 70$ years) for diagnostic esophagogastroduodenoscopy (EGD). Respiratory depression, time to full recovery, and overall patient satisfaction were evaluated and blood concentrations of propofol were measured. Study 2: A subset of subjects undergoing diagnostic EGD were randomized to receive $40 \mathrm{mg}$ of propofol $(n=30), 4$ mg of midazolam $(n=30)$ or no sedation controls $(n=20)$, and the residual effects of each drug were tested using a driving simulator. The primary outcome measure was driving ability. The second outcome measures were overall patient satisfaction and complications. Results: Study 1: Only $1.1 \%$ of 12,031 healthy subjects developed transient oxygen desaturation. Full recovery was present in $97.5 \% 30$ min after the procedure; $99.8 \%$ were willing to repeat the same procedure. The blood levels of propofol (40$80 \mathrm{mg}$ ) at $60 \mathrm{~min}$ were $<100 \mathrm{ng} / \mathrm{ml}$. Study 2: Driving ability
\end{abstract}

recovered to the basal level within $60 \mathrm{~min}$ of propofol administration but not with $120 \mathrm{~min}$ with midazolam. There were no complications; overall patient satisfaction was similar between propofol and midazolam (8.9 vs. 8.5, $\mathrm{p}=0.34$ ). Conclusion: Low-dose propofol sedation was safe and recovery including driving ability was with $60 \mathrm{~min}$.

Copyright $\odot 2008$ S. Karger AG, Basel

\section{Introduction}

Screening esophagogastroduodenoscopy (EGD) for the detection of early gastric cancer is widely practiced in Japan and many individuals undergo an annual diagnostic EGD. The desire for a comfortable EGD experience has resulted in an increasing prevalence of the intravenous sedation in Japan. Although many patients wish to drive soon after diagnostic EGD, driving is usually prohibited if intravenous sedation was administered. Propofol is a good candidate for the sedative agent in diagnostic EGD in that it is superior to benzodiazepines with regard to rapidity of induction of sedation and is associated with faster recovery. However, the possibility of respiratory depression has made many endoscopists reluctant to use propofol routinely [1-11].

Here we report a prospective investigation of nurseadministered bolus injections of low-dose of propofol (40-80 $\mathrm{mg}$ for those $<70$ years and $30 \mathrm{mg}$ for those $\geq 70$ years) for diagnostic EGD. We evaluated the results in

\section{KARGER}

Fax +4161306 1234 E-Mail karger@karger.ch www.karger.com

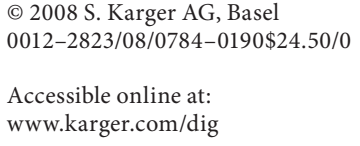

Akira Horiuchi, MD

Department of Gastroenterology

Showa Inan General Hospital

3230 Akaho, Komagane 399-4191 (Japan)

Tel. +81 26582 2121, Fax +81 26582 2118, E-Mail horiuchi.akira@sihp.jp 
terms of complications, recovery rate, and overall patient satisfaction. The blood concentration of propofol (40 and $80 \mathrm{mg}$ ) was also measured. We used a driving simulator to compare the residual effects of propofol with those of midazolam on psychomotor function.

\section{Patients and Methods}

We prospectively evaluated low-dose propofol sedation administered by a nurse supervised by the endoscopist. Both the nurses and endoscopists had advanced cardiac life support (ACLS) certification. The study was done at the Showa Inan General Hospital and the study was conducted in accordance with the Helsinki Declaration and was approved by the ethics committee at the hospital. Verbal and written informed consent was obtained from all subjects. Subjects were excluded if they were less than 18 years old, pregnant, assigned to American Society of Anesthesiologists (ASA) class III and IV, overweight (body weight $>100 \mathrm{~kg}$ ), or allergic to the drugs used or its components (soybeans or eggs). Monitoring included continuous assessment of peripheral oxygen saturation $\left(\mathrm{SpO}_{2}\right)$ and heart rate. Clinical assessment of the patient, including measurement of respiratory effort by visual assessment and by palpation of the chest wall and abdominal excursion and/or palpation of exhaled breath, was performed routinely. When oxygen desaturation $\left(\mathrm{SpO}_{2}<90 \%\right)$ continued more than $20 \mathrm{~s}$, supplemental oxygen was given. The endoscopic team consisted of the nurse administering drugs and responsible for the patient, the endoscopist, and a second nurse to assist the endoscopist and the patient monitoring nurse.

\section{Study 1}

EGD was performed in the lateral decubitus position. Subjects received topical pharyngeal anesthesia with lidocaine. Propofol (Duprivan, AstraZeneca, Japan) was given by a bolus injection with a standard protocol of $40 \mathrm{mg}$ for subjects $<70$ years old and $30 \mathrm{mg}$ for subjects age 70 or over. Adequate sedation was generally achieved when the subject passed through the following sequence: eyes closing, one or two yawns, and cessation of body movements. The target level of sedation was moderate conscious sedation with subjects still being able to respond purposefully to verbal commands. When its target level was not obtained or the subjects were undersedated, an additional injection of 20 or $40 \mathrm{mg}$ of propofol was given. However, in no instance was more than 80 mg given. A decline in $\mathrm{SpO}_{2}$ to less than $90 \%$ was regarded as respiratory depression associated with the sedation. In addition to monitoring of vital signs, the subjects' condition was also assessed more globally by visual inspection. Monitoring and complications were recorded by a registered nurse.

Subjects were moved to the waiting room after they could stand by themselves and they were discharged after they were fully awake. Full recovery, including consciousness and psychomotor function was assessed using three criteria: (1) level of consciousness (fully awake and responding to questions from the recovery room nurse); (2) ability to stand on one-foot, and (3) ability to walk in a straight line for 5 meters without instability. These three criteria were assessed every 15 min starting $30 \mathrm{~min}$ after the procedure; full recovery was defined as meeting all three criteria. The nurses reconfirmed the absence of reemerging seda- tive effects and finally permitted patients to leave the endoscopic unit. The subjects were asked about willingness to repeat the same procedure next time (yes/no) to assess their overall satisfaction for this procedure.

In a subset of subjects, the blood concentrations of propofol were measured before and 5, 30, 60 and 120 min after a bolus injection of $40 \mathrm{mg}(\mathrm{n}=25)$ or $80 \mathrm{mg}(\mathrm{n}=12)$ in order to evaluate the relation between the residual effects of propofol and their blood levels.

\section{Study 2}

Eighty healthy subjects undergoing diagnostic EGD were randomized to receive a bolus injection of $40 \mathrm{mg}$ of propofol $(\mathrm{n}=30)$, $4 \mathrm{mg}$ of midazolam $(\mathrm{n}=30)$, or no sedation (controls $=20)$. Patients were assigned randomly to the three groups using sealed opaque envelopes. Prior to the procedure driving ability was measured using a driving simulator and this was repeated before and 30,60 , and 120 min after drug administration. The control group did not receive any sedative drugs and also had driving ability evaluated using the same protocol. The primary outcome measure was the time when the driving ability was equivalent to that measured before the procedure. The second outcome measures were overall patient satisfaction and complications.

The levels of overall satisfaction were assessed by using a 10$\mathrm{cm}$ visual analog scale (VAS), where 10 equaled excellent and 0 equaled poor [12]. The subjects were asked about their willingness to repeat the same procedure next year (yes/no). Within $48 \mathrm{~h}$ after the procedure, patients were contacted by telephone and asked about complications that might have developed after discharge.

\section{Driving Simulation}

Driving ability is a sensitive indicator of residual drug effects [13]. All subjects performed a 10-min divided attention driving simulation test (DADST) after a 5-min practice session using a commercially available simulator (DS-20, Mitsubishi Precision, Tokyo, Japan) that was located within the endoscopy unit. The subjects sat in front of a monitor and used a steering wheel, accelerator, and brakes to control the vehicle. The road scene display changed in accordance with the subject's actions. The object of the test was to steer an image of a car bonnet down the center of a winding road as accurately as possible (measuring the ability to track) using a steering wheel. During the test crossing pedestrians appeared randomly on the screen and often attempted to cross the road of the computer screen. To test vigilance and reaction time the subjects were required to properly identify and respond to the behavior of pedestrians. The results of the DADST were expressed as tracking error (standard deviation from the center of the road), accelerating reaction time (average time respond to pedestrians), and braking reaction time (average time respond to pedestrians).

\section{Blood Concentrations of Propofol}

The measurement of blood concentration of propofol was performed according to previously described methods [14, 15]. For the measurement of propofol, acetnitrile and internal standard added to a plasma sample and vortexed for $1 \mathrm{~min}$. After centrifugation at 13,000 rpm for $5 \mathrm{~min}, 50$-liter aliquots of the supernatant were directly injected into the HPLC system involving a C18 reverse-phase column. Propofol and the internal standard (thymol) were quantified using a coulometric electrochemical detection. 


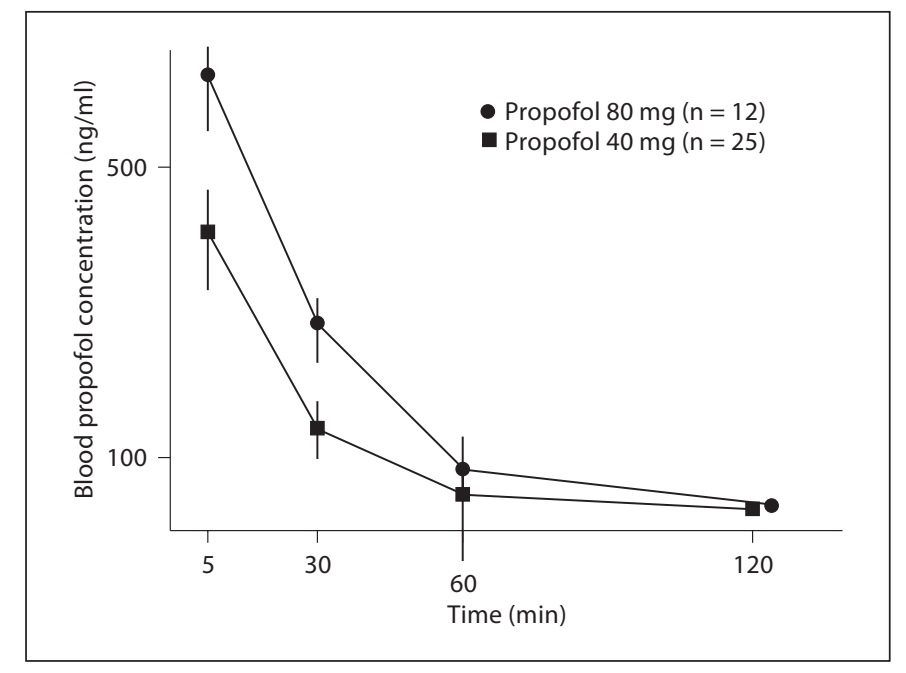

Fig. 1. Relation between blood concentrations of propofol after bolus injections of propofol (40 and $80 \mathrm{mg}$ ) and time course.

\section{Statistical Analysis}

Data are presented as means and SDs. Statistical tests to compare the measured results among the three groups were as follows: $\chi^{2}$ test, with Yates' correction for continuity where appropriate, was used for comparison of categorical data; the Fisher exact test was used when the numbers were small. The Kruskal-Wallis test was used for ordinal variables of nonparametric data. For parametric data, analysis of variance was used when three and more means were compared and positive results were confirmed using Dunnett's procedure. $\mathrm{p}<0.05$ was regarded as significant. All statistical evaluation was performed by using SPSS version 12.0J software (SPSS Japan Inc., Tokyo, Japan).

\section{Results}

\section{Study 1}

Between January, 2003 and December, 2006, diagnostic EGD was performed in 12,031 healthy subjects using the low-dose propofol sedation $(30-80 \mathrm{mg})$ (table 1$)$. The subjects' age ranged from 18 to 84 years. Propofol (60-80 $\mathrm{mg})$ was required in $4 \%(\mathrm{n}=482)$, all of whom were less than 70 years of age. 6,188 subjects (51\%) underwent EGD for cancer screening. A biopsy was taken in 991 subjects (8.2\%). The procedure time of EGD in almost all subjects was 5 to $8 \mathrm{~min}$. Oxygen desaturation requiring supplemental oxygen occurred in $1.1 \%$; mask ventilation or endotracheal intubation were not required in any case. In no case did prolonged apnea or laryngospasm occur. Full recovery $30 \mathrm{~min}$ after the procedure was present in $97.5 \%, 100 \%$ of the subjects completely recovered $60 \mathrm{~min}$
Table 1. Demographic and clinical data for 12,031 healthy subjects who underwent diagnostic EGD using low-dose propofol sedation

\begin{tabular}{lc}
\hline Male & $7,827(65)$ \\
Mean age, years (range) & $57.7(18-87)$ \\
Body weight, $\mathrm{kg}$ (range) & $32-95$ \\
Propofol sedation (30-40 mg) & $11,549(96)$ \\
$\mathrm{SpO}_{2}<90 \%$ & $234(1.9)$ \\
Oxygen administered & $129(1.1)$ \\
Prolonged apnea & $0(0)$ \\
Full recovery rate 30 min after the procedure & $11,931(97.5)$ \\
Full recovery rate 60 min after the procedure & $12,031(100)$ \\
Willingness to repeat the same procedure & $12,001(99.8)$ \\
\hline
\end{tabular}

Values represent numbers (\%), unless indicated otherwise. EGD = Esophagogastroduodenoscopy.

after the procedure, and $99.8 \%$ of the subjects agreed to repeat the same sedation for their next screening examination.

The relation between the blood concentrations of propofol after a bolus injection of propofol (40 or $80 \mathrm{mg}$ ) and the time course is shown in figure 1. The population, which was analyzed for blood level metabolism of propofol, was comparable to the population presented in table 1 .

Blood propofol concentrations at $60 \mathrm{~min}$ after injection of propofol (40 or $80 \mathrm{mg}$ ) were less than $100 \mathrm{ng} / \mathrm{ml}$.

\section{Study 2}

Table 2 shows demographic and clinical profiles of subjects participating in the comparative study of propofol, midazolam, or neither (controls). There were no complications and overall patient satisfaction on a 10-point VAS was similar between propofol and midazolam (8.9 vs. $8.5, \mathrm{p}=0.34$ ). Driving skills (tracking errors, accelerating reaction time, and braking reaction time) recovered to the basal levels in all subjects receiving propofol within $60 \mathrm{~min}$ of administration. On the other hand, the midazolam group had significantly more tracking errors $(57 \pm 6 \%$ vs. $86 \pm 8 \%)$ and slower reaction times (0.52 \pm $0.3 \mathrm{~s}$ vs. $0.89 \pm 0.5 \mathrm{~s}$ ) at $120 \mathrm{~min}$ (table 3 ).

\section{Discussion}

The advantages of propofol in comparison with benzodiazepines as a drug for endoscopic conscious sedation include almost immediate onset of action and fast recov- 
Table 2. Comparison between healthy subjects who received propofol versus those who received midazolam

\begin{tabular}{|c|c|c|c|c|}
\hline & $\begin{array}{l}\text { Propofol } \\
(\mathrm{n}=30)\end{array}$ & $\begin{array}{l}\text { Midazolam } \\
(\mathrm{n}=30)\end{array}$ & $\begin{array}{l}\text { Control } \\
(\mathrm{n}=20)\end{array}$ & $\begin{array}{l}\mathrm{p} \\
\text { value }\end{array}$ \\
\hline Age, years & $56 \pm 17$ & $52 \pm 14$ & $55 \pm 11$ & 0.67 \\
\hline Male & 21 & 19 & 11 & 0.56 \\
\hline $\begin{array}{l}\text { Mean body weight, kg } \\
\text { EGD indication }\end{array}$ & $62 \pm 11$ & $59 \pm 12$ & $61 \pm 9$ & 0.71 \\
\hline Screening & 24 & 22 & 17 & 0.60 \\
\hline GI symptoms & 6 & 8 & 3 & 0.30 \\
\hline EGD duration, min & $6.2 \pm 0.7$ & $6.5 \pm 1.2$ & $6.1 \pm 0.9$ & 0.74 \\
\hline $\mathrm{SpO}_{2}<90 \%$ & 0 & 1 & 0 & \\
\hline Oxygen administered & 0 & 1 & 0 & \\
\hline Heart rate $<50$ beats/min & 0 & 0 & 0 & \\
\hline $\begin{array}{l}\text { Complication within } 48 \mathrm{~h} \\
\text { after procedure }\end{array}$ & 0 & 0 & 0 & \\
\hline Overall satisfaction* & $8.9 \pm 1.0$ & $8.5 \pm 1.2$ & $6.6 \pm 1.8$ & 0.0017 \\
\hline $\begin{array}{l}\text { Willingness to repeat the } \\
\text { same procedure, } \%\end{array}$ & 100 & 93 & $85 \%$ & 0.0013 \\
\hline
\end{tabular}

EGD = Esophagogastroduodenoscopy.

Values represent mean \pm SD. ${ }^{*}$ Scale $0-10$, where 10 is excellent and 0 is poor. Overall satisfaction between propofol and midazolam; $8.9 \pm 1.0$ vs. $8.5 \pm 1.2, \mathrm{p}=0.34$

ery. This report describes our experience in terms of safety and overall satisfaction with nurse-administered lowdose propofol given to 12,031 healthy subjects undergoing diagnostic EGD. Previous reports have involved propofol dosages ranging from 30 to $300 \mathrm{mg}$ for endoscopic sedation [1-11]. The protocol adopted in our study strongly focused on the safety and the initial dose of 30 or $40 \mathrm{mg}$ of propofol was designed to minimize hypoxemia during the EGD. Significant respiratory compromise $\left(\mathrm{SpO}_{2}<90 \%\right)$ was rare compared with previous reports $[16,17]$ and no subject required mechanical ventilation during the procedures via either endotracheal intubation or a mask.

All propofol sedated patients regained normal neuropsychological function within $30 \mathrm{~min}$ after the procedure $[11,16]$. In previous reports, the average time until full recovery was $15-20 \mathrm{~min}$ and the average time to discharge was $60 \mathrm{~min}$. Sanou et al. [18] conducted five cognitive tests designed to assess short-term memory, delayed memory, the ability to plan complex tasks, attention, and language comprehension following propofolsedation and reported that cognitive functions were still depressed after $3 \mathrm{~h}$. Riphaus et al. [19] recommended that patients remain in a supervised environment for at least
Table 3. Diving ability before and at 30,60 and 120 min after injection of each drug

\begin{tabular}{|c|c|c|c|}
\hline & \multicolumn{3}{|l|}{ Driving ability } \\
\hline & $\begin{array}{l}\text { tracking } \\
\text { error }\end{array}$ & $\begin{array}{l}\text { accelerating } \\
\text { RT }\end{array}$ & $\begin{array}{l}\text { braking } \\
\text { RT }\end{array}$ \\
\hline \multicolumn{4}{|l|}{ Propofol group $(n=30)$} \\
\hline Before & $32 \pm 2.7 \%$ & $0.56 \pm 0.21$ & $0.66 \pm 0.34$ \\
\hline 30 min after injection & $74 \pm 3.2 \% *$ & $0.88 \pm 0.34^{*}$ & $0.56 \pm 0.54$ \\
\hline $60 \mathrm{~min}$ & $45 \pm 2.3 \%$ & $0.43 \pm 0.32$ & $0.49 \pm 0.28$ \\
\hline $120 \mathrm{~min}$ & $37 \pm 1.9 \%$ & $0.34 \pm 0.17$ & $0.32 \pm 0.31$ \\
\hline \multicolumn{4}{|c|}{ Midazolam group $(n=30)$} \\
\hline Before & $57 \pm 5.7 \%$ & $0.52 \pm 0.26$ & $0.45 \pm 0.21$ \\
\hline 30 min after injection & Not tested & Not tested & Not tested \\
\hline $60 \mathrm{~min}$ & $156 \pm 16.7 \% * *$ & $1.06 \pm 0.51^{* *}$ & $0.88 \pm 0.34^{*}$ \\
\hline $120 \mathrm{~min}$ & $86 \pm 7.7 \% *$ & $0.89 \pm 0.49^{*}$ & $0.56 \pm 0.41$ \\
\hline \multicolumn{4}{|l|}{ Control group $(n=20)$} \\
\hline Before & $32 \pm 2.7 \%$ & $0.56 \pm 0.31$ & $0.76 \pm 0.41$ \\
\hline $30 \mathrm{~min}$ & $46 \pm 3.1 \%$ & $0.46 \pm 0.28$ & $0.55 \pm 0.27$ \\
\hline $60 \mathrm{~min}$ & $39 \pm 2.9 \%$ & $0.66 \pm 0.43$ & $0.46 \pm 0.52$ \\
\hline $120 \mathrm{~min}$ & $31 \pm 1.7 \%$ & $0.57 \pm 0.34$ & $0.54 \pm 0.33$ \\
\hline
\end{tabular}

$\mathrm{RT}=$ Reaction time (second). ${ }^{*} \mathrm{p}<0.05,{ }^{* *} \mathrm{p}<0.01$ Significantly different from before (baseline level) in each group.

$3 \mathrm{~h}$ after propofol sedation and that patients refrain from driving and unescorted use of public transport for $24 \mathrm{~h}$ after sedation. However, these recommendations followed studies where the propofol dosages were $105 \pm 60$ $\mathrm{mg}$, which is significantly more than the $30-40 \mathrm{mg}$ dosage used here.

Generally, propofol is given by bolus titration with an initial dose of 30-50 mg followed by doses of 10-20 mg beginning 30-60 s later with the appropriateness of additional bolus doses being determined by the level of sedation and the respiratory effect. This approach requires the use of highly skilled personnel. In contrast, we used a defined protocol where, depending on the patient age, either 30 or $40 \mathrm{mg}$ was given by bolus injection. As shown in table 2, the average weight of the healthy Japanese subjects was about $60 \mathrm{~kg}$ such that the dosage used averaged $0.67 \mathrm{mg} / \mathrm{kg}$. Using this dosage we showed driving ability returned to baseline within 60 min after completion of the EGD and $98 \%$ of the 12,031 subjects fully recovered to the basal level $30 \mathrm{~min}$ after the procedure. This differs remarkably from the effects of midazolam where impaired driving was still present at $2 \mathrm{~h}$ after the procedure (table 3). 
A previous study examined the relationship between blood alcohol concentration and psychomotor effects and attempted to provide a standard based on the maximum permitted blood alcohol levels for driving in three European countries $(20,50$ and $80 \mathrm{mg} / 100 \mathrm{ml})$ as the reference points [13]. The impairment in driving skill with a blood propofol concentration of $200 \mathrm{ng} / \mathrm{ml}$ was less than that observed with a $50 \mathrm{mg} / 100 \mathrm{ml}$ of alcohol and not greater than that observed with $20 \mathrm{mg} / 100 \mathrm{ml}$ of alcohol [13]. These results are consistent with our findings that driving levels recovered to the baseline level when the blood levels of propofol ( 40 and $80 \mathrm{mg}$ ) at $60 \mathrm{~min}$ were less than $100 \mathrm{ng} / \mathrm{ml}$ (fig. 1; table 3).
Screening EGD for early gastric cancer is a health initiative that is more relevant to the Japanese population. On the other hand, colonoscopy is more relevant in the Western population where the median body weight is likely to be much higher than $60 \mathrm{~kg}$. The results of this report are applicable to a patient population comprising healthy outpatients undergoing diagnostic EGD. For patients undergoing colonoscopy or therapeutic endoscopic procedures, additional doses of propofol and combination of other drugs may be required.

In conclusion, low-dose propofol sedation for diagnostic EGD was safe and clinical recovery and recovery in driving ability was rapid.

\section{References}

1 Koshy G, Nair S, Norkus EP, Hertan HI, Pitchumoni CS: Propofol versus midazolam and meperidine for conscious sedation in GI endoscopy. Am J Gastroenterol 2000;95: 1476-1479.

-2 Sipe BW, Rex DK, Latinovich D, et al: Propofol versus midazolam/meperidine for outpatient colonoscopy: administration by nurses supervised by endoscopists. Gastrointest Endosc 2002;55:815-825.

$\checkmark 3$ Rex DK, Overley C, Kinser K, et al: Safety of propofol administered by registered nurses with gastroenterologist supervision in 2000 endoscopic cases. Am J Gastroenterol 2002; 97:1159-1163.

4 Walker JA, McIntyre RD, Schleinitz PF, et al: Nurse-administered propofol sedation without anesthesia specialists in 9152 endoscopic cases in an ambulatory surgery center. Am J Gastroenterol 2003;98:1744-1750.

$\checkmark 5$ Heuss LT, Schnieper P, Drewe J, Pflimlin E, Beglinger C: Risk stratification and safe administration of propofol by registered nurses supervised by the gastroenterologist: a prospective observational study of more than 2000 cases. Gastrointest Endosc 2003;57: 664-671.

6 Heuss LT, Schnieper P, Drewe J, Pflimlin E, Beglinger C: Safety of propofol for conscious sedation during endoscopic procedures in high-risk patients-a prospective, controlled study. Am J Gastroenterol 2003;98:17511757.
Külling D, Rothenbühler R, Inauen W: Safety of nonanesthetist sedation with propofol for outpatient colonoscopy and esophagogastroduodenoscopy. Endoscopy 2003;35: 679-682.

$\checkmark 8$ Cohen LB, Dubovsky AN, Aisenberg J, Miller KM: Propofol for endoscopic sedation: a protocol for safe and effective administration by the gastroenterologist. Gastrointest Endosc 2003;58:725-732.

$\checkmark 9$ Cohen LB, Hightower CD, Wood DA, Miller KM, Aisenberg J: Moderate level sedation during endoscopy: a prospective study using low dose propofol, meperidine/fentanyl, and midazolam. Gastrointest Endosc 2004;59: 795-803.

10 Rex DK, Heuss LT, Walker JA, QI R: Trained registered nurses/endoscopy teams can administer propofol safely for endoscopy. Gastroenterology 2005;129:1384-1391.

11 Tohda G, Higashi S, Wakahara S, Morikawa M, Sakumoto H, Kane T: Propofol sedation during endoscopic procedures: safe and effective administration by registered nurses supervised by endoscopists. Endoscopy 2006;38:360-367.

$>12$ Revill SI, Robinson JO, Rosen M, Hogg MI: The reliability of a linear analogue for evaluating pain. Anesthesia 1976;31:1191-1198.

13 Grant SA, Murdoch J, Millar K, Kenny GNC: Blood propofol concentration and psychomotor effects on driving skills. Br J Anaesth 2000;85:396-400.
14 Tanaka E, Terada M, Misawa S, Wakasugi C: Simultaneous determination of twelve benzodiazepines in human serum using a new reversed-phase chromatographic column on a 2-microns porous microspherical silica gel. J Chromatogr [B] 1996;682:173-178.

15 Ubel RA, Wium CA, Hawtrey AO, Coetzee J: Electrochemical determination of 2, 6-diisopropylphenol after high-performance liquid chromatography of extracts from serum. J Chromatogr 1990;526:293-295.

16 Vargo JJ, Zuccaro G, Dumot JA, et al: Gastroenterologist-administered propofol versus meperidine and midazolam for advanced upper endoscopy: a prospective, randomized trial. Gastroenterology 2002;123:8-16.

17 Vargo JJ, Zuccaro G, Dumot JA, Shay SS, Conwell DL, Morrow JB: Gastroenterologist-administered propofol for therapeutic upper endoscopy with graphic assessment of respiratory activity: a case series. Gastrointest Endosc 2000;52:250-255.

18 Sanou J, Goodall G, Capuron L, BourdalleBadie C, Maurette P: Cognitive sequelae of propofol anaesthesia. Neuroreport 1996;7: 1130-1132.

19 Riphaus A, Gstettenbauer T, Frenz MB, Wehrmann T: Quality of psychomotor recovery after propofol sedation for routine endoscopy: a randomized and controlled study. Endoscopy 2006;38:677-683. 